\section{Novos significados da mobilidade}

\author{
Eduardo Marandola Jr. ${ }^{*}$
}

CRESSWELL, Tim. On the move: mobility in the modern western world. New York: Routledge, 2006. 327p.

A mobilidade é um dos fenômenos mais importantes da sociedade contemporânea. Trata-se de elemento fundamental da dinâmica demográfica e de interesse direto de vários pesquisadores, pois congrega uma série de fenômenos imprescindíveis para compreender as transformações no mundo atual. A mobilidade - meio utilizado para acessar outros serviços ou bens ocupa hoje posição de atora dos processos. Migrar não é mais simplesmente fugir, sendo que os deslocamentos pendulares, transnacionais e de curta duração em grandes distâncias têm tido impactos cada vez mais significativos na dinâmica socioespacial contemporânea.

Apesar disso, a mobilidade só há pouco tempo tem sido abordada de forma mais ampla, dissociando-a de uma mera componente quantitativa de mensuração de fluxos de A para $B$. O fenômeno da mobilidade envolve uma série de fatores e processos distintos que estão, ao mesmo tempo, na base estrutural do sistema produtivo e no cotidiano vivido das pessoas, englobando todo o sistema de transportes e a gestão pública desses espaços, passando pela forma urbana, as interações espaciais até as dinâmicas demográficas específicas (estrutura familiar, migração, ciclo vital). Urge um olhar mais amplo sobre a mobilidade, que não a associe de forma direta e rasteira ao deslocamento físico, mas que Ihe conceda os atributos de um fenômeno propriamente dito.
O livro do geógrafo Tim Cresswell, On the move: mobility in the modern westrn world, editado pela Routledge, em 2006, busca realizar tal ambicioso intento. É um dos mais completos estudos recentes sobre o fenômeno. O autor não faz uma análise descritiva de tipos de mobilidade ou de formas e padrões de mobilidade, mas mergulha no fenômeno em busca de suas correlações e seu significado atual. $O$ itinerário intelectual de Cresswell na temática inicia-se com sua dissertação de mestrado, defendida em 1986, analisando as metáforas da mobilidade nas letras de Bob Dylan. Sua tese avançou sobre as metáforas na cultura popular norte-americana, mergulhando assim nos significados da mobilidade enquanto estilo de vida no país que inventou a mobilidade contemporânea, via automóvel. Com a importância crescente da mobilidade desde meados dos anos 90, quando tornouse um "paradigma", o autor investe no tema agregando elementos em busca de uma leitura mais ampla da mobilidade e de suas principais questões atuais.

O livro tem nove capítulos nos quais Cresswell explora, de forma muito inventiva e criativa, alguns aspectos da mobilidade atual, desde os home offices, os direitos de mobilidade, as mobilidades imigrantes e as mobilidades nos aeroportos. Há capítulos que discutem ainda a captura da mobilidade pela fotografia, além da dança enquanto mobilidade.

O primeiro capítulo é aquele que traça o itinerário de leitura, procurando uma reflexão epistemológica sobre o significado da mobilidade e suas possibilidades analíticas. $A$ produção da mobilidade é entendida pelo autor como bifacial: uma face corporal e outra social. Dissociando a idéia da mobilidade como mero movimento, Cresswell se afasta de uma metáfora muito ampla para a mobilidade (de capitais, mobilidade social etc.), enfatizando aquela realizada por pessoas e grupos. O movimento ou deslocamento é o processo que leva corpos de A para B. A mobilidade é mais ampla, pois é social, envolve estruturas, meios, cultura e significado.

\footnotetext{
* Geógrafo, pesquisador colaborador do Núcleo de Estudos de População, Universidade Estadual de Campinas (Nepo/ Unicamp).
} 
Cresswell chama atenção ainda para a importância de rediscutir a fórmula "compressão espaço-tempo", já que as diferentes escalas de tempo e espaço impõem um repensar sobre o significado dessa relação espaço-tempo. Uma simples compressão não explica a mobilidade atual nem o impacto do transporte contemporâneo em termos de experiência do lugar.

O capítulo epistemológico termina com uma visão histórica dos sentidos da mobilidade, passando pelo sentido feudal, da baixa modernidade e da modernidade ocidental de forma geral, resultando numa geosofia crítica da mobilidade. Geosofia é o nome dado à geografia do conhecimento, aquela que considera a dimensão imaterial da experiência das pessoas e suas imaginações. E a visão crítica de Cresswell é assim explicitada por ele:

By critical geosophy, I mean an examination of the way geographical concepts structure and enable practice in the world. Specifically, this book considers the role played by mobility and, necessarily, relative immobility, in people's geographical imaginations. These imaginations, I argue, are not simply colorful mental maps confined to the world of ideas. Rather they are active participants in the world of action. They inform judges, doctors, factory managers, photographers, government officials, lawyers, airport planners, and all manner of other people with the ability to mold the world we live in. They escape the bonds of individual dreams and aspirations and become social. They become political. (p.21)

A multidimensionalidade da análise de Cresswell é uma de suas maiores virtudes, permitindo um pano de fundo conceitual para pensarmos as questões mais diversas que envolvem a mobilidade, seja numa análise mais focada em movimentos específicos, seja num esforço maior de apreender o significado de grandes processos. Em vista disso, On the move é uma leitura obrigatória para os estudiosos de população, pois, se a mobilidade não é mais um mero número de fluxos casa-trabalho ou campo-cidade, mas sim um dos fenômenos sociais mais importantes e complexos do nosso tempo, é necessário mergulhar nos seus significados para podermos entendê-lo em suas várias dimensões. A reflexão de Cresswell, nesse sentido, é riquíssima e fundamental para pensar a mobilidade na contemporaneidade.

Recebido para publicação em 28/02/2008. Aceito para publicação em 25/04/2008. 